Chapter 5

\title{
The Importance of Partnerships in Promoting Entrepreneurship Education - Case Study of a Group of Schools
}

\author{
Maria Isabel Carvalho and Mário Franco \\ Additional information is available at the end of the chapter \\ http://dx.doi.org/10.5772/58869
}

\section{Introduction}

The importance of entrepreneurial activity to the economy is well founded, particularly in the areas of economic growth and job creation [1, 2]. Schools and universities across the world have been actively engaged in the study of entrepreneurship and the development of an entrepreneurship curriculum in recent years $[3,4,5,6]$. The field of entrepreneurship has been one of the most topical areas of study in education in schools and universities throughout the world. Although formal education in Europe has not promoted entrepreneurship and independent employment, attitudes and cultural references are developed from childhood [7, 8] and so education can play a fundamental role in responding to the challenge of entrepreneurship in Europe [9] and particularly in Portugal.

Gert-Jan Koopman of the European Commission stated that entrepreneurship education really affects the number of young people choosing to start up their own business in the future. But although the majority of adolescents think schools are conscious of the need to provide their pupils with competences in the area of management, few feel that their school does this effectively [10, 11].

Traditional teaching methods and the normal classroom context do not promote the development of capacities and skills essential in the modern business world. Scholars have written much on what should be taught in entrepreneurial education. A review of the literature shows that entrepreneurship education should include skill-building courses in negotiation, leadership, new product development, creativity and innovation [12].

Identification of opportunities has also been seen as a critical entrepreneurial skill that should be included in an entrepreneurship curriculum $[13,14]$. Educating students about entrepre- 
neurship and how to become more entrepreneurial are also significant components of entrepreneurial education [15]. Understanding the role of partnerships, clients and other stakeholders have been identified as important entrepreneurial concepts [16, 17]. New educational experiences based on project work have therefore been incorporated in curricula, in order to stimulate the skills and capacities essential in working life [18] and to respond to the greater complexity and uncertainty the individual, as a worker, has to face in a globalized world $[19,20]$.

In this context, Entrepreneurship Education Programmes (EEP) have proliferated in Portugal in recent years, similarly to what has happened in other European countries [16, 21], at all levels of education, promoted not only by the respective Ministries but also by private entities [22], leading to the formation of inter-organizational relations and partnerships.

Access to partnerships is a critical resource as many types of economic behavior, including change of career path and exchange of information or tangible resources between actors, are influenced by social relations [23, 24]. Entrepreneurial activities are likewise dependent on personal networks, as these can provide the necessary knowledge, employees or capital in situations of uncertainty $[25,26]$. Interaction with entrepreneurs in partnerships can also provide inspiration and "mental models" i.e. sets of entrepreneurial behaviors, attributes and consequences that can be observed and imitated by other partnership members [27]. However, the involvement of actors from both academia and industry in partnerships can be more difficult to achieve since there are considerable differences in the norms and modes of operation between schools and firms [28, 29, 30].

This study used the concept of partnerships between School and Community to designate the relationships formed between the School and individuals, organizations and firms in the community, aiming to promote the integral development of children/teenagers, giving them significant pedagogical experiences [31,32] which, due to the wide-ranging nature of the resources involved, the school would not be able to provide on its own. Indeed, there is a lack of literature and studies on School - Community partnerships, in promoting entrepreneurship education. Despite Entrepreneurship Education Programmes (EEP) exploring the existing literature and best practices of other regional programmes, little research and few programmes exist of this type in secondary schools.

To fill this research caveat, this study aims to understand the need to form partnerships to promote entrepreneurship education, how those partnerships are characterized, the obstacles faced in forming and maintaining these relationships and their success factors. Therefore, this study intends to respond to two research questions: (1) What is the structure and functioning of the relationships formed by the school with local and regional bodies to promote entrepreneurship education? and (2) What is the contribution of the relationships formed by the school with local and regional bodies to promote entrepreneurship education? This study intends, therefore, to make a contribution to theory in the areas of entrepreneurship and strategic management and it serves as a benchmark model for others in the development of similar regional, collaborative organizations to foster entrepreneurship education. 
The remainder of the chapter is structured as follows: Section 2 presents a review of the literature on inter-organizational relationships, some characterization of school-community partnerships and some considerations regarding EEP. Section 3 presents the methodology used, followed by analysis and discussion of the results in Section 4. Conclusions, contributions, limitations and future lines of research are also presented.

\section{Literature review}

\subsection{Partnerships/inter-organizational relationships}

The justification for forming inter-organizational relationships is theoretically well founded, given the diversity of theoretical paradigm [33] explaining those relationships Transaction Costs Theory [34], Resource Dependency Theory [35], Stakeholder Theory [36], Organizational Learning Theory [37] and Institutional Theory [38]. These multiple contributions coming from social sciences such as Economics, Sociology or Management, reflect the fragmentation in the literature and is also the consequence of the multi-faceted nature of inter-organizational relationships, which often involve a combination of motivations, intentions and objectives $[33,39]$.

Since none of these theories alone completely explain the establishment of inter-organizational relationships [39], this study takes the contributions of Resource Dependency Theory [35] and the Theory of Overlapping Spheres of Influence [40]. This author argues that schools implementing practices that promote strong school, family and community partnerships should be more able to help children succeed academically because these outreach activities create greater consistency between children's home and school contexts. School, Family and the Community are responsible for children's socialization and education and share common objectives with regard to children/young people, such as their overall development and scholastic success, which will be more easily attained through joint action [37]. The need to join forces and unite support in the community arises from the multiplicity and specificity of the resources required to fulfil educational projects relevant for preparing children and young people for the challenges of today's society, which are unlikely to be within the reach of each school per se [37, 41].

Inter-organizational relationships can take various forms, including alliances [70], interorganizational networks [39] and others, which can be distinguished by the intensity of the connection between participants [33]. In [41] partnership structures are likely environments for implementation of educational projects aiming to develop the skills and competences that contribute to increased human capital, with this being defined from a broad perspective as the set of academic qualifications and formal and informal skills held by an individual.

In reference [42] the concept of'social partnership' as a form of collaborative, voluntary and temporary action in which organizations from different sectors, both public and private, interact to reach common objectives, namely solving complex social problems reflecting a common concern that is in some way identified as an aspect of the public policy agenda that 
one organization would not be able to deal with individually. The objectives of social partnerships are normally established so as to have a short or long-term impact on a given area of public policy, but their most immediate objective benefits participants directly, without which there would be no incentive for collaborative interaction.

In [42] is also presented a typology of social partnerships based on the characteristics of the problem to be solved in collaboration, namely its complexity or extent and the hierarchical level of the partner organizations for which the problem is relevant. Therefore, this author presents three types of social partnerships: systemic, federative and programmatic.

When the problem is relatively complex, the number of organizations involved will be greater and it will concern partners' highest hierarchical levels. In this case, the partnership will be of the systemic type. However, if the problems to be solved concern a specific group of actors, only a small number of key organizations will be involved and the hierarchical level concerned in solving the problem will be intermediate (or high, in the case of smaller organizations). In this case, the partnership will be of the federative type. Then again, when the problems are relatively structured, they require the interaction of fewer organizations and the lowest hierarchical level will be involved. In this case, the partnership will be of the programmatic type, since its focus will be on developing specific programmes to respond to partners' needs [42].

\subsection{Partnerships between school and community}

The importance of space and place has been increasingly recognized in the literature on interorganizational partnerships as an aspect of their structure and functioning. In this connection, the concept of social capital has been applied to identify social norms and customs incorporated in the social environment with the characteristic confidence of each environment, which is frequently tacit and specific to each community [43].

Face-to-face communication is an important way of creating trust between individuals due to the investments of effort, money and time manifest when people come together [44]. It has also been shown that face-to-face contacts facilitate learning, provide motivation and are an effective mode of communication due to an increased capacity for interruption and feedback $[44,45]$.

When developing partnerships, mobility of individuals is an effective mechanism and can even be deemed essential for initial partnership formation to take place since it is a prerequisite for face-to-face meetings and interaction [46].

In this context, partnerships between School and Community are formed based on social interaction, on mutual trust and on the relationships that promote diligence in the community, which may be susceptible to abuse in the scope of power relationships. More isolated, backward, rural communities present quite different characteristics from metropolitan areas, which may be seen as challenges and simultaneously opportunities for establishing partnerships. Those characteristics are of an economic, social, educational and scholastic nature and allow the affirmation that despite the possible shortage of human capital and economic 
resources in rural communities, they have great social capital as a result of existing relationships and this should be taken advantage of [31].

Higher relationship intensity between schools and firms, defined, for example, in personnel exchanges, was linked to higher levels of tangible outcomes from the relationships. The industrial experience of academics involved in school-industry partnerships is an important success factor and that mobility through visits is a fruitful way of learning about each other's needs and wants [47].

In [48] the importance of cooperation between schools and the business sector in creating innovative pedagogical practices able to develop fundamental capacities in young people to make them future citizens, considering partnerships between schools and the local community as essential in building the foundations of an innovative and sustainable society. In reference [48] are also mentioned learning processes, often in the form of partnerships, alliances, networks and more flexible relationships between the school and other local institutions, corroborating the possibility of moving the boundaries between systems of education, training and work pointed out by [49], in pursuing a common goal - enabling young people.

Despite these advantages, the difficulty of finding partners in a rural, economically depressed and limited region as one of the barriers to partnerships. In addition, other obstacles to the formation of partnerships with the community were identified in the study by [32], namely the non-existence of suitable leadership in schools able to develop, assess and coordinate those partnerships, the attitude of some school teachers and heads in considering the community is indifferent to, or lacking the resources that could contribute to pupils' scholastic success or the fear in schools and their professionals of being exposed to public scrutiny.

In [48] also point out tensions and challenges in establishing and maintaining partnerships between schools and other community bodies, namely, the reluctance of some organizations to cooperate with schools other than their own, and vice-versa, the obligation to provide young people with learning that has meaning for them and is valued by the job market, the need to maintain permanent communication between the school and its partners, and the difficulty in measuring the success of partnerships regarding determination of the effects of participation in them and the advantages in continuing with them.

Another challenge in forming and maintaining partnerships is the need to involve parents as partners, particularly in stimulating education programmes and obtaining their support, due to the fact that they are becoming an increasingly powerful pressure group, able to influence the school curriculum insofar as this concerns the quality of the children's education [20,48].

Against this background, in [31] points out as an indispensable factor for the formation of a successful partnership, the school having a type of leadership that abandons traditional and behavioural models and follows relational models, promoting trust, empathy, comprehension of others' ideas and perceptions, the ability to establish commitments, dialogue and harmony. In reference [18], the need for strategic thinking in schools able to provide a cultural change in education, so that school experiences promote the development of competences appropriate to the demands of today's society, such as the ability to solve problems, continuous learning 
and creative thought. The formation of partnerships implies that the parties share a common and mutual interest in a joint activity [18].

\subsection{Education Entrepreneurship Programmes (EEP)}

It is not surprising there have been a large number of initiatives developed worldwide to promote a broad range of entrepreneurial activities within academic institutions [50]. These include programmes to develop new organisations as well as projects that link the school to businesses within the region [51,52].

In the last two decades, entrepreneurship education has expanded significantly in most industrialized countries [53], as the number of courses in entrepreneurship has continued to increase, both in Europe [54, 55], and in the United States of America [56, 57].

Compared to many other disciplines, that of entrepreneurship is in its infancy, with no standard framework or agreed best practices for entrepreneurial education $[7,8]$. There is even some debate among scholars as to the wisdom of teaching students to become entrepreneurs in the light of current teaching pedagogy $[58,59]$. However, there is sufficient empirical data to conclude that students can be taught entrepreneurial competencies [56], and in reference [57], "the question of whether entrepreneurship can be taught is obsolete".

Standing out among the entrepreneurial competences triggered by education, some authors $[60,61]$ mention increased knowledge in the field of entrepreneurship, creativity, the sense of opportunity, the ability to take on risks and cope with uncertainty and responsibility. Nevertheless, the central set of skills in this century includes the ability to solve analytical problems, innovation and creativity, taking the initiative, flexibility and adaptability, critical thought and communication and collaboration skills $[62,63]$, skills that are also appreciated by future employers [11, 64].

To transmit this knowledge and these competences to young people, some programmes have appeared. However, this study highlights the EMPRE Programme. This Project of "EMPRESchool Entrepreneurs", conceived from the programme of Young European Business (EJE), developed by Valnalón, a Spanish public company, is a Programme of Education in Entrepreneurship (EEP) directed to the 3rd Cycle of Basic Education, Secondary and Professional Education, in which the methodology is based on pupils themselves creating and managing a mini-firm at school during an academic year [22].

The aim of the EMPRE Project is to instil and encourage entrepreneurial and personal skills, highlighting the following: responsibility and organization; expression and communication; initiative and creativity; teamwork and cooperation; interpersonal relations and sociability (Proposal for Pedagogical Intervention EMPRE - School Entrepreneurs AEVH 2009).

EMPRE was implemented in Portugal in the academic year of 2009/2010 in four schools (a school group) in a region in central Portugal (Mação), with a total of 202 pupils. In the 2012/2013 academic year, the project was extended to more than 400 pupils throughout the Central Region. 
The project has a consultant supporting the classes involved, a collaborator from Tagusvalley, with the task of managing the period of each phase of the project-17 in total-, helping to structure the organization of classes, providing additional information and advice to both pupils and teachers, and facilitating links between teachers, schools and other bodies (Presentation of EMPRE Methodology). The project also includes a clarification session for teachers and parents/guardians.

In the 2009/2010 school year, the EMPRE project included at the initial stage visits to schools by local business-people, to share with pupils their experiences as entrepreneurs, and a visit by pupils to a firm in the region. At the end of each school year, an "EMPRE Fair" is held, an event where all participating mini-firms are present, with the objective of displaying and selling their products/services.

\section{Methodology}

\subsection{Type of study and case selection}

Given the exploratory nature of the study and the research questions, the case studyqualitative approach- is seen to be the most appropriate method. The case study method was chosen for this research because it offers a suitable mechanism for exploring in depth, areas that have little well developed theory and it has demonstrated this value in the social sciences, particularly in relation to schools and the community. Cases, especially exploratory case studies, are also an effective mechanism for the development of theory $[65,66]$.

This study was limited to exhaustive study of partnerships in an entity, the Verde Horizonte Group of Schools (AEVH) in Mação, Portugal, and is therefore an intensive study of a specific state education institution. The option to carry out the research in a single state school followed the criterion of analysing a school in an inland region of the country which is predominantly rural, depressed and distant from major centres, and comprehension of partnerships formed by the school with local and regional bodies to promote entrepreneurship education. Choosing this school in particular was not based on the conviction it was representative of Portuguese state schools, but rather through being a school in the inland region belonging to the Network of Schools of Excellence (ESCXEL), which has provided its pupils, at the various levels of education, with various programmes of entrepreneurial education (EEP), from the academic year of 2009/2010. One of the programmes in entrepreneurial education developed was that of "EMPRE-Business at School", promoted by Tagusvalley-Vale do Tejo Technological Centre, resulting from the formation of a set of partnerships between the School Group and various local and regional bodies, which this study aims to analyse and understand. The figure below shows the partners involved in implementing this programme to stimulate entrepreneurial education in AEVH. 


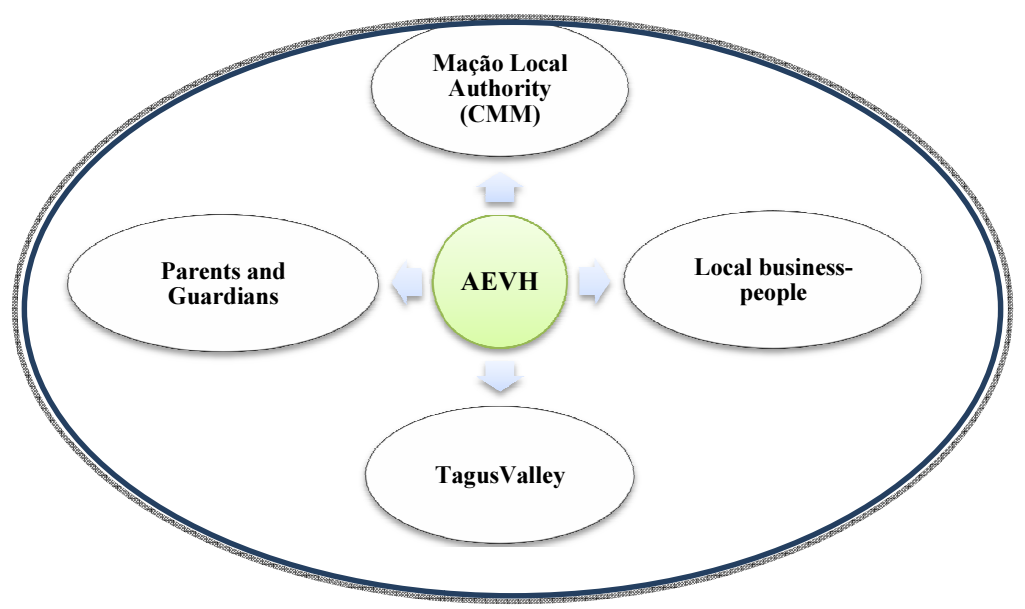

Figure 1. Stakeholders involved in the partnerships

\subsection{Data-collecting instruments}

The data collection process involved several documents provided by the organizations and interviews. This use of multiple data sources and the subsequent ability to examine several documents provided good triangulation [67]. Initially, therefore, data collection was carried out through documentary analysis and subsequently through interviews with some of the stakeholders/partners. Parents and business-people were not interviewed in this study. Data is triangulated [68] where possible in order to determine replicable information and denounce inconsistent information in an attempt to minimize the subjectivity of the data presented. The names of individuals/partners have been anonymized.

The first phase of data-collection began by identifying the documents that in each partner would be most likely to contain useful information for understanding the partnerships formed in the scope of promoting education in entrepreneurship. Document selection was based on criteria of their availability and their relevance for analysis of the partnerships formed by AEVH. Table 1 shows the documents analyzed from the three partners involved in this study.

\begin{tabular}{lll}
\hline \multicolumn{1}{c}{ CMM } & \multicolumn{1}{c}{ AEVH } & \multicolumn{1}{c}{ Tagusvalley } \\
\hline Article on the CMM Activity Plan & Educational Project 2009-2011 & $\begin{array}{l}\text { EMPRE project's online platform } \\
\text { (www.empre.org) }\end{array}$ \\
\hline $\begin{array}{lll}\text { Educational Charter of Mação Local } \\
\text { Authority }\end{array}$ & Curricular Project 2010-2013 & $\begin{array}{l}\text { Regulations of the Vale do Tejo } \\
\text { Technological Centre }\end{array}$ \\
\hline & Proposal for EMPRE Pedagogical & \\
& Intervention & \\
\hline
\end{tabular}

Table 1. Documents analysed and their institutions of origin 
Then, during May and June 2013, semi-structured interviews were held with the Head of the Verde Horizonte Group of Schools, and in each of the partner organizations the person responsible for forming relations with the school group was identified, regarding the EMPRE project: in Mação Local Authority (CMM), the mayor was interviewed, and in Tagusvalley, the coordinator of the EMPRE project.

All interviews were based on the same protocol/guide. They were arranged previously by telephone, according to the interviewees' availability, and took place on the premises of the respective organizations. Each interview lasted approximately thirty minutes and was recorded, allowing data to be stored and facilitating the organization and analysis of the information (Table 2).

\begin{tabular}{llllll}
\hline \multicolumn{1}{c}{ Interviewee's post } & Institution & $\begin{array}{c}\text { Age of } \\
\text { interviewee }\end{array}$ & Date of interview & Place of interview & $\begin{array}{c}\text { Duration of } \\
\text { interview }\end{array}$ \\
\hline Head & AEVH & 48 years & $21 /$ May/2013 & $\begin{array}{l}\text { At AEVH, } \\
\text { Mação }\end{array}$ & 35 minutes \\
\hline $\begin{array}{l}\text { Coordinator of the } \\
\text { EMPRE project }\end{array}$ & Tagusvalley & 36 years & 27/May/2013 & $\begin{array}{l}\text { At Tagus Valley, } \\
\text { Abrantes }\end{array}$ & 30 minutes \\
\hline Mayor & $\mathrm{CMM}$ & 53 years & 6/June/2013 & $\begin{array}{l}\text { At CMM, } \\
\text { Mação }\end{array}$ & 25 minutes \\
\hline
\end{tabular}

Table 2. Interviews and key informants

\section{Case study analysis and discussion}

Regarding data treatment, due to the information sources being documents and interviews, content analysis [69] was chosen, a technique that allows analysis of the content of literary information in an objective and systematic way.

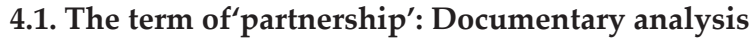

A first reading of the content of the documents selected aimed to discover how inter-organizational partnerships were mentioned in the documents analyzed. To this end, specific expressions/terms were looked for, namely, partnership, relationship, relation, network, cooperation, collaboration, agreement and protocol. ${ }^{1}$ The diversity of expressions sought arises, firstly, from the multiplicity of specific forms inter-organizational relationships can take on [33, 70], and secondly, from not expecting the choice of expression used in mentioning inter-organizational partnerships in the documents selected to adhere to rigorous scientific criteria.

Table 3 summarizes the analysis made, indicating the number of times each expression appears in each document and in what context. 


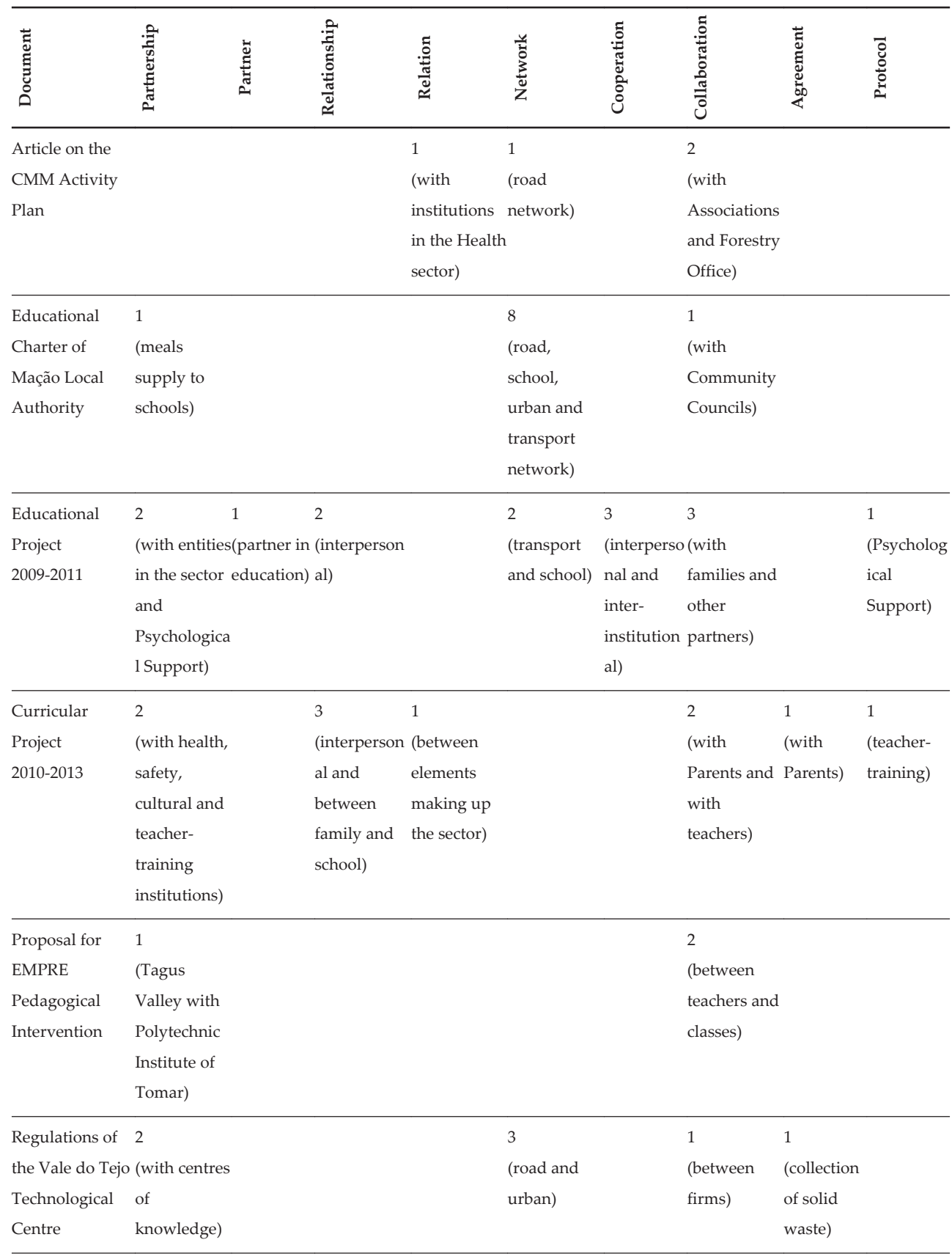

EMPRE project's3

online platform 


\begin{tabular}{|c|c|c|c|c|c|c|c|c|c|}
\hline $\begin{array}{l}\vec{\Xi} \\
\text { İ } \\
\text { ڤ. }\end{array}$ & 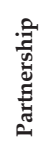 & 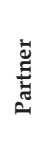 & 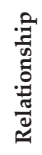 & 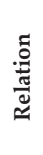 & $\begin{array}{l}\text { uे } \\
\text { ż } \\
\text { ż }\end{array}$ & 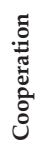 & 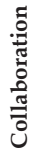 & 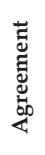 & $\begin{array}{l}\overline{0} \\
\stackrel{0}{0} \\
\text { d }\end{array}$ \\
\hline & \multicolumn{4}{|c|}{ (R\&D and } & \multicolumn{5}{|c|}{ (of EMPRE } \\
\hline & \multicolumn{4}{|c|}{ various } & \multicolumn{5}{|c|}{ project } \\
\hline & \multicolumn{4}{|c|}{ entities for } & \multicolumn{5}{|c|}{ partners) } \\
\hline & \multicolumn{9}{|c|}{ entrepreneur } \\
\hline & \multicolumn{9}{|c|}{ ship } \\
\hline & \multicolumn{9}{|c|}{ education) } \\
\hline
\end{tabular}

Table 3. Documentary analysis - Expressions referring to inter-organizational relations

From the documentary analysis presented in Table 3, it can be observed that it is documents issued by $\mathrm{AEVH}$ that make most frequent reference to specific relationships concerning interorganizational partnerships, particularly with entities in the field, and more exactly with parents and families.

As for the Local Authority (CMM) documents, despite the content denoting commitment to the educational success of pupils in the area and the will show to make CMM resources which could contribute to that end available to $\mathrm{AEVH}$, in those documents there is no specific use of expressions related to partnerships with $\mathrm{AEVH}$, with one exception regarding the supply of school meals.

Concerning the documents from Tagusvalley, it is of note there is only one explicit reference to partnerships with various entities in the sphere of entrepreneurship education, among which we can naturally include schools, and AEVH in particular. Despite the lack of use of expressions, there is a clear commitment to the purpose common to all the partnership organizations this study intends to analyse, which includes particularly young people's integral development and keeping them in the district.

\subsection{Partnership characterization}

Regarding classification of the type of partnerships formed by AEVH in the sphere of entrepreneurship education, we can consider these are partnerships of a pragmatic type due to the small number of actors involved and because the problem to be solved is relatively structured and its focus is the development of a specific programme. Therefore, the hierarchical level involved in the AEVH partnerships analysed is the highest in each of the partner organizations, which can be considered contrary to the characterization of [42]. However, if we take into account that both AEVH and CMM are institutes coming within Central Administration, the hierarchical level of the actors involved is relative.

Some of the documentation analysed also allowed assessment of the typology of the relations formed between the partners identified here, particularly the fact these relationships are longlasting, habitual and wide-ranging with regard to their scope and diversity of partners, based on appreciation of the environment. In this respect, they involve geographically close organ- 
izations, and although generically foreseen in these organizations' fundamental documents, they do not need any more specific regulation to develop.

In these circumstances, there is clear evidence of cooperation among actors/partners, which although subject to legislative formalities, takes place with a considerable degree of informality in interaction in terms of transfer of knowledge, communication and information. The sharing of experiences can be informal, promoting contacts. In this way, a path to strengthening intranetwork links is begun, allowing the acquisition and construction of social capital.

This informality in the partnerships formed is confirmed in the statements of the three interviewees:

- "It is a close and informal relationship - the formality only exists to set up that relationship" (Mayor of CMM).

- "Annual non-formalized, automatically renewable protocol, if none of the parties backs out" (Person in charge of Tagusvalley)

- "Informal partnerships, but they are starting to become usual, without there being a formalized protocol - the repeated informality gives way to unwritten formalization" (Head of AEVH).

It was also possible to characterize the relationships between the three organizations studied. Those relationships are reciprocal and long-lasting, are not limited to a single area and are based on trust between the people leading them, with bonds resulting from prolonged contact, provided by not only geographical but also ideological proximity. Inasmuch, the evidence of this case study corroborates the work of [31] and [43] on the importance of space and place and social capital for the type of relationships that emerge in a community, especially a rural, isolated and depressed one, such as the one studied here.

\subsection{Reasons for forming partnerships}

The three interviewees are clearly in harmony regarding the reasons at the origin of forming the partnerships analysed. There is a common purpose taken to be the fundamental motivation for each of the organizations involved, this being an increase in the region's human capital. According to the interviewee from CMM, "there is a clear will on the part of CMM to give special prominence to the area of entrepreneurship, contributing to raising the awareness of young people, to the region's benefit (...). The target population is concentrated in the schools". In the view of this organization, quality education allows new horizons to be opened up, with the final objective being that young people become responsible, entrepreneurial adults who return to the district to give of their best.

For the coordinator of the EMPRE programme (Tagusvalley), "partnering with entities that pursue the same objectives (...) and improving the region's economic and business situation, stimulating the number of entrepreneurs in the medium/long term and innovation". The partners share common goals-"development of personal skills, the pupil's personal development and preparation for future job markets". 
Also on the motives for forming partnerships, the head of AEVH mentions"accessing the experience and support for the logistics the project involves - human resources, financial support and transport". The head goes on to highlight "the opening of doors provided by the partners allows the school to participate in other forums". In this way, the partners share common aims - "all want to provide pupils with educational experiences that are varied, meaningful and of quality - quality of education is a goal for all the partners".

On analyzing some documents from the organizations studied, we see a description of some of these objectives/motives in forming partnerships to promote entrepreneurship education (Table 4.).

\section{Article on the CMM Activity Plan of 2008 \\ “...the Local Authority Executive will continue to pay special attention to school-age children, as was the case in previous years, supplying a set of essential services and support for their personal and academic enhancement." \\ Educational Charter of Mação-Mação Local Authority (CMM):}

- "... the school, as the centre of educational policies, must entities"

build its autonomy with regard to the surrounding community, its potential and problems, relying on a new attitude in Local, Regional and Central Administration that will allow a better response to the challenges of change."

-“(...) Mação Local Authority intends to attain a major objective: "to promote quality education in all its schools, providing children and young people in Mação Council with identical or better opportunities than those offered in urban areas."

- "Being considered a strategic sector for the Local Authority's development, Education, ... , so that our children have training and development facilities which can prepare them to face the future with sufficient skills on which to base the success we all desire for each one of them in particular and for the Council area in general." - "AEVH will be provided with a set of equipment and services able to add quality to educational/training tasks at all levels of education (...). Besides providing this equipment and services, CMM will supply a transport network which will allow, in addition to transport to schools, a set of extra-curricular activities, in this way broadening educational horizons."

\section{Educational Project of AEVH 2009-2011}

"The school, in assuming its prominent position in

EDUCATION FOR CITIZENSHIP, will develop practices towards COMPLETE EDUCATION OF THE HUMAN BEING and will adopt strategies that allow ... contributions to highlighting the role of the school in its environment, by forming partnerships with different Objectives: “To provide, in collaboration with educational partners, formal and informal teaching/learning situations that stimulate the expression of interests and aptitudes in the various domains of training."

"... the problems were identified: ...lack of parental involvement in school life...".

\section{Curricular Project of AEVH 2010-2013}

“...this new school orientation assumes it will develop a in close relationship between its integral parts and the surrounding environment..."

"...there is an absolute necessity for correct articulation of the curricular orientations issued nationally with the real situation of the school's environment."

"...in this Curricular Project, the following goals are defined as priorities: (1) promoting strategies that contribute to a better relationship between the family and the school/parental involvement; (2) establishing greater school/community interaction; and (3) forming partnerships with various institutions in the areas of safety, health and culture."

"The interests of families and the community should also be reflected in that curriculum..."

Table 4. Documentary analysis: Reasons for partnerships 
The interviews confirm the alignment of all partners regarding a socially relevant objective, valued by all those involved - successful integrated development and the educational success of the region's children and young people. In particular, the head of AEVH stated in his interview that" all (the partners) want to provide pupils with educational experiences that are varied, meaningful and of quality - quality in education is a goal for all the partners". These organizations pursue certain common objectives, assuming that as a group they achieve what would not be possible individually [71].

Concerning recognition, by all partners, of a common purpose behind establishing the partnership, the evidence obtained in this case study confirms what is stated in the literature $[40,48,49]$.

In the three interviews, there is evidence of recognition of the School's authority as an institution responsible for leading the educational process, and particularly in the field of entrepreneurship. The agreement by CMM and Tagusvalley, in recognizing their role as partners of AEVH, is not surprising, and considering the literature quoted [48], since this is a school within these institutions' area of influence, their willingness to cooperate could even be expected.

In the interview, the head of AEVH also mentions the need for resources to promote entrepreneurship education, which the school does not possess and therefore needs to obtain outside, pointing to the synergies between organizations as a motivation/advantage of the partnerships formed. Indeed, the need to get hold of resources from community institutions to develop educational projects at school is an aspect highlighted in the literature $[37,41]$.

It can also be seen from the documentary analysis that CMM refers to the dimension of the resources in at least one of the documents analysed and its willingness to provide them for educational and school use. Although the documents originating in AEVH do not refer specifically to the need for those resources, they strongly underline the intention to form and strengthen partnerships with entities in the surrounding area, recognizing the authority/ influence they have or could have locally and in the educational process, particularly parents and families.

Table 4 confirms that all the organizations involved in the partnership clearly identify in the respective documents a socially relevant objective for the medium/long term, which is valued by all partners: the successful integrated development of the district's children and young people. Forming partnerships with other local organizations with a view to that medium and long-term objective is evident in the documents originating in AEVH. That objective is accepted as the purpose of establishing the partnerships analysed, and is common to all those involved.

\subsection{Obstacles in forming partnerships}

Through its Educational Project 2009-2011, AEVH identifies as a barrier/obstacle to partnership with families, the remoteness of parents and guardians from school life, stating that their active participation in school activities is a success factor of that partnership. On the other hand, the Local Authority's Educational Charter, a document produced by CMM, recognizes the 
authority/influence of the School concerning educational services, and even its autonomy, while showing the CMM organization's strategy of collaborating with the School in carrying out its mission.

It is also of note that none of the interviewees referred to the role of parents or the need to involve them in achieving education for entrepreneurship, and in particular, in the EMPRE project, despite their involvement being foreseen in the project's supporting documentation. In this particular aspect of the involvement of parents as partners in activating entrepreneurship education programmes, the evidence of this study does not confirm the conclusions of [20] and [48] that parents are becoming a pressure group able to influence the school curriculum, despite recognizing their authority and desiring their intervention and collaboration in those programmes. Indeed, in the documents guiding $\mathrm{AEVH}$, there is an expressed wish to involve parents and families in school life, but their remoteness is also mentioned and considered a barrier to forming partnerships with these actors.

At this moment, the challenge for AEVH seems to be to get parents involved somehow in the activities developed at school rather than obtaining their support for decisions concerning the curriculum to implement. The lack of parental effort in implementing EEP, in particular, could be due to considering it as an exclusive sphere of action for the school and its professionals, regarding the school curriculum and the trust placed in the community's institutions to lead these programmes.

This study does not confirm reluctance by the school and its professionals to be exposed to public scrutiny nor an attitude of mistrust by teachers or the head regarding the community's legitimacy to contribute to pupils' scholastic success, as has been mentioned in the literature on School-Community partnerships, namely in the study by [20]. However, in the interview with the head of $\mathrm{AEVH}$, it is evident there is a certain discomfort in elements of the school caused by the loss of absolute control of the process, as a result of forming partnerships. Despite that and the merely informal appreciation of the results of the partnerships, their continuation assumes the result is positive.

The following quotations give other empirical evidence of the barriers felt by the partners involved in these inter-organizational partnerships.

- "The universe of young people focused on could perhaps mean a limited success rate. Partners' participation in school activities could be more frequent, partners could devote more time to the relationship with the school (...). The existence of specific funding to channel to EMPRE could benefit the relationship" (Mayor of CMM).

- "The absence of a global strategy for the medium and long term of educational authorities to take advantage of existing resources implies work repeated annually in launching the partnership" (Tagus Valley coordinator). Also for the person in charge of this organization, "the EMPRE Project begins very late in each school year, due to the need to repeat each year the process of launching the partnership with the school, because of the lack of a global policy and m.l.p. of the educational authorities". The"lack of funds, the need to contact the school administration at the start of each school year to renew the partnership, leading to a delay in beginning the EMPRE Project in the school year" $^{\prime \prime}$, is also pointed out by the EMPRE coordinator as a barrier forming partnerships. 
In this context, the head of AEVH underlines that the "partnerships imply a loss of absolute control of the process, a loss of decision-making capacity and immediate intervention. The EMPRE Project appears to be already formatted, necessitating adjustment without the possibility of altering the format; lack of accompaniment in the $3^{\text {rd }}$ edition (...)".

The head of this Group of Schools also highlights that"there are not many institutions that can add unequivocal bonuses in a project of entrepreneurship education (...). There is "little diversity of partners and partners do not have enough time to deal with the school's needs". The lack of finance was another obstacle identified by this interviewee in implementing EEP in the school.

\subsection{Factors of partnership success}

For the success of the partnerships, the Mayor of CMM and the coordinator from Tagusvalley pointed out the style of leadership exercised by the head of $\mathrm{AEVH}$, this being of a relational type. The following quotations show other success factors:

- "The existence of careful planning, constructive dialogue between partners, appropriate school leadership that is appropriate, involved, dedicated and resilient" (Mayor of CMM).

- "Relationships based on personal bonds, friendship, proximity, personal and institutional trust, institutional tradition (...). Partnerships are long-lasting and should remain ad eternum, they cover various areas", the Mayor of CMM also states.

- "The existence of careful annual planning; constructive dialogue that has led to adaptations to the EMPRE project (...). Appropriate leadership in AEVH - the head is very focused on the matter of entrepreneurship education (...); intervention with other community actors, leading to partnership functioning, which benefits the project's application" (Coordinator from Tagusvalley).

- "Relationships are based on trust, personal bonds, geographical proximity, institutional tradition, they are long-lasting and not limited to the EMPRE Project" (Tagus Valley).

This evidence agrees with the conclusions in the work by [18] and [31], who mention leadership as a determinant factor of success of partnerships between School and Community, as well as the need for strategic thinking in schools that values school experiences promoting the development of appropriate skills for the demands of today's society. It is noted that it was not possible to associate any evidence of these factors in the content of the documentation analysed.

In his interview, the head of AEVH also accepts that one of the success factors of the partnerships formed is"the effort by those directly responsible for implementing the EMPRE project in the school, recognizing the importance and need for the involvement of human resources for partnership success and the role of intermediate leadership as determinant for the success of the partnerships formed in the scope of the EMPRE project".

The interviewee from the School Group also stresses as factors of partnership success, "careful planning and constructive dialogue; leadership is important, namely intermediate leadership, i.e., by the project coordinators in the school; relationships based on trust, the personal knowledge of those in 
charge, proximity, institutional tradition", that is to say, "long-lasting relationships that go beyond EMPRE".

In fact, trust has also been identified as an important variable determining whether a partnership can be maintained or not. In [60] it is necessary to pay greater attention to the partnership processes. Factors such as trust, commitment, open communication, flexibility and the capacity to manage conflicts should be considered. Indeed, in a partnership it is important to communicate easily with potential stakeholders to minimize resistance to its creation and maintenance.

Another question arising from the interviews held was the reference by the head of AEVH and the leader of Tagus Valley to "organizational learning" achieved through the partnerships formed, which ties in with the conclusion of [48]. Learning processes are often the result of partnerships between schools and local institutions, corroborating the possibility of going beyond the boundaries of education, training and work systems, as proposed by [49].

\section{Conclusions and implications}

This chapter seeks to highlight the role of partnerships in entrepreneurship education programmes to encourage the growth of entrepreneurial motivations in secondary schools. Educational institutions have the role of educating and preparing individuals to become employees [55]. Self-employment or entrepreneurship has not been traditionally viewed as a career choice for graduates. Thus, this traditional role needs to be reformed because the world is changing.

The literature highlights the importance of promoting entrepreneurial skills among students [19]. However, the overwhelming majority of curricular programmes do not contemplate contents related to entrepreneurship, teachers have no specific training in the subject and the formal educational system itself does not contribute to developing skills commonly associated with entrepreneurship. Nevertheless, schools, and particularly those in charge of them, are aware of the need to equip young people with these skills, and so they have embarked on partnerships with local and regional bodies in order to give their pupils the possibility of benefiting from Programmes of Education in Entrepreneurship.

The Verde Horizonte Group of Schools (AEVH) studied here is an example of a school organization which, to meet some needs for specific resources to activate those programmes, but contained in a collaborative strategy with local and regional actors, formed a set of partnerships with organizations that could add some unequivocal advantages regarding education in entrepreneurship. Those partnerships are based on the social network characterizing the region which is predominantly rural, depressed and remote from major centres, have an influential role in the school's organization and are founded on leadership of a relational nature exercised by the head $\mathrm{AEVH}$, recognized both internally and in the community. 
Based on the evidence obtained, alignment of all partners was found towards a socially relevant objective valued by all those involved-successful integrated development and the educational success of the region's children and young people.

This study was also able to conclude that the involvement of parents and guardians is not yet what would be wished for, according to the intentions expressed in the empirical evidence, and is not a true partnership regarding education in entrepreneurship. This fact arises from the study as the most obvious obstacle to the functioning of partnerships between the schools and community analysed, with a long way to go in relation to the influence and authority of this actor in the school context. Therefore, we believe that the Entrepreneurship Education Programme presents a viable model for fruitful inter-school collaboration and cooperation in entrepreneurship programming. The evidence so far indicates that it has been highly successful after only three years of operation. We suggest this model may be very useful to other regional groupings of entrepreneurship centres, as long as the geographical spread is not too great and the collaboration maintains its focus. We think the region will also reap the benefit of our efforts in the long run.

Several implications for policymakers and leaders of academic institutions follow on from the results presented here. There is a need to involve parents in defining a strategy of education in entrepreneurship. Entrepreneurship education should be included in the Educational Project of AEVH as an objective for the school, so that all the institution's teachers (and other actors) identify with that objective, their efforts can be assessed within that parameter and entrepreneurship education projects are not abandoned by the institution when the teachers involved leave.

There is also the need to reward the teachers involved in the dynamics of EEP (for example, through assessing their performance). There may be a risk of abandoning the defined strategy for entrepreneurship education, if and when institutional leaders are replaced in their respective posts, since the partnerships formed are based essentially on the informal and even personal bonds existing between them. It is therefore necessary/advantageous to define nationally a strategy for entrepreneurship education in state schools.

Those in charge should implant the vision that entrepreneurship education is not the exclusive responsibility of the school and that the sphere of action can and should be occupied by other institutions in the community, for example, companies and business associations, whose technical knowledge is indispensable for the dynamics of entrepreneurship education.

Students involved in such courses and programmes could serve as inspiration and role models for new and prospective students, while at the same time strengthening the ties between a school and other parts of the society/community.

This study is not without its limitations. One of them lies in the fact it was not possible to obtain statements from representatives of all the organizations identified as forming part of AEVH's relationships. This limitation prevented, for example, perception of the role represented by parents in defining the school curriculum. With parents being considered in the literature as an increasingly powerful pressure group, this is an unavoidable question in understanding 
the partnerships described. Inclusion of that actor is therefore suggested for analysis in future research, so that the data obtained are more wide-ranging, giving more depth to conclusions. Another limitation of this study arises from the method used - study of a single case- which, despite being the most appropriate for this research, presents the disadvantage of not allowing generalization of conclusions. Data were analyzed for a single Group of Schools, in a specific context, and so generalization of the conclusions of this study to other cases is not possible, due to its specific characteristics, such as the social and business situation, cultural aspects, educational structure and geographical location, among other determinants of the type of relationships formed between School and Community.

As a future line of research, we suggest developing this investigation in a significant number of schools with triangulation of research methods, resorting to methods of a quantitative nature, so that a comparative analysis can be made with generalization of the results obtained.

\section{Author details}

Maria Isabel Carvalho ${ }^{1}$ and Mário Franco ${ }^{2 *}$

*Address all correspondence to: mfranco@ubi.pt

1 University of Beira Interior, Covilhã, Portugal

2 University of Beira Interior, Management and Economics Department, CEFAGE-UBI Research Center, Covilhã, Portugal

\section{References}

[1] Gibb, A. A. (1996). Entrepreneurship and small business management: Can we afford to neglect them in the twenty-first century business school? British Journal of Management, 7(4), 309-324.

[2] Reynolds, P. D., Camp, M., Bygrave, W. D., Autio, E., \& Hay, M. (2001). Global entrepreneurship monitor: 2001 executive report. Kansas City, MO: Kauffman Center for Entrepreneurial Leadership.

[3] Vesper, K. H., \& Gartner, W.B. (1997). Measuring progress in entrepreneurship education. Journal of Business Venturing, 12(5), 403-421.

[4] Solomon, G.T., Duffy, S., \&Tarabishy, A. (2002). The state of entrepreneurship education in the United States: a nationwide survey and analysis. International Journal of Entrepreneurship Education, 1(1), 65-86. 
[5] Henry, C., Hill, F., \& Leitch, C. (2003). Entrepreneurship Education and Training. Ashgate, Aldershot.

[6] Politis, D. (2005). The process of entrepreneurial learning: a conceptual framework. Entrepreneurship Theory and Practice, 29(4), 399-424.

[7] Solomon, G. T. (2007). An examination of entrepreneurship education in the United States. Journal of Small Business Enterprise Development, 14(2), 168-182.

[8] Brockhaus, R., Hills, G., Klandt, H., \& Welsch, H. (2001). Entrepreneurship education: A global view. Aldershot, U.K.: Avebury.

[9] European Commission (2006). Aplicar o Programa Comunitário de Lisboa: promover o espírito empreendedor através do ensino e da aprendizagem, Comissao Europeia, Bruxelas.

[10] Anonymous. (2006). Young people feel they need better training in entrepreneurship. Education \& Training, 48(2/3), 197-200.

[11] Dhillon, J. K. (2013). Senior managers' perspectives of leading and managing effective, sustainable and successful partnerships. Educational Management Administration $\mathcal{E}$ Leadership, 41(6), 736-750.

[12] McMullan, W. E., \& Long, W. A. (1987). Entrepreneurship education in the nineties. Journal of Business Venturing, 2, 261-275.

[13] Shane S., \&Venkataraman S. (2000). The Promise of Entrepreneurship as a Field of Research. Academy of Management Review, 25, 217-226.

[14] Hindle, K. (2004). A practical strategy for discovering, evaluating, and exploiting entrepreneurial opportunities: Research-based action guidelines. Journal of Small Business and Entrepreneurship, 17, 267-276.

[15] Rae, D. (2000). Understanding entrepreneurial learning: a question on how. International Journal of Entrepreneurial Research, 6(3), 129-144.

[16] Gibb, A. A. (1993). The enterprise culture and education: Understanding enterprise education and its links with small business, entrepreneurship and wider educational goals. International Small Business Journal, 11(3), 11-34.

[17] Taylor, D. W., \& Thorpe, R. (2004). Entrepreneurial learning: a process of co-participation. Journal of Small Business and Enterprise Development, 11(2), 203-11.

[18] Lethbridge, D., \& Davies, G. (1995). An initiative for the development of creativity in science and technology (CREST): an interim report on a partnership between schools and industry. Technovation, 15(7), 453-465.

[19] Gibb, A. A. (2002). In pursuit of a new enterprise and entrepreneurship paradigm of learning: creative destruction, new values, new ways of doing things and new combinations of knowledge. International Journal of Management Reviews, 4(3), 233-269. 
[20] Cotton, J. C. (1993). Developing enterprising teaching and learning in Hungary. Education \& Training, 35(7), 8.

[21] Hytti, U., \& O'Gorman, C. (2004). What is "enterprise education"? An analysis of the objectives and methods of enterprise education programmes in four European countries. Education \& Training, 46(1), 11-23.

[22] Carvalho, M. I., Simões, J., Samagaio, A., \& Couto, E. (2012). Enterprise Potential of Portuguese Students Fostered by an Entrepreneurship Education Program. Proceedings of ECIE12 7th European Conference on Innovation and Entrepreneurship, pp.68-78, listed in the Thomson Reuters ISI Index Social Sciences \& Humanities Proceedings (ISSHP/ISI Proceedings), (ISBN: 978-1-908272-68-3).

[23] Granovetter, M. (1985). Economic action and social structure: The problem of embeddedness. American Journal of Sociology, 91(3), 481-510.

[24] Granovetter, M. S. (1974). Getting a job: A study of contacts and careers. Cambridge, MA: Harvard University Press.

[25] Aldrich, H., Rosen, B., \& Woodward, W. (1987). The impact of social networks on business foundings and profit: A longitudinal study. In N. C. Churchil, J. A. Hornaday, B. A. Kirchhoff, O. J. Krasner, \& K. H. Vesper (Eds.), Frontiers of entrepreneurship research. Proceedings of the seventh annual Babson college entrepreneurship research conference. Wellesley, MA: Babson College.

[26] Shane, S., \& Cable, D. (2002). Network ties, reputation, and the financing of new ventures. Management Science, 48(3), 364-381.

[27] Fornahl, D. (2003). Entrepreneurial activities in a regional context. In D. Fornahl\& T. Brenner (Eds.), Cooperation, networks and institutions in regional innovation systems (pp. 38-57). Cheltenham, UK: Edward Elgar.

[28] Klofsten, M., \& Jones-Evans, D. (2000). Comparing academic entrepreneurship in Europe: The case of Sweden and Ireland. Small Business Economics, 14(4), 299-309.

[29] Fisher, D., \& Atkinson-Grosjean, J. (2002). Brokers on the boundary: Academy-industry liaison in Canadian universities. Higher Education, 44(3), 449-467.

[30] Mosey, S., Lockett, A., \&Westhead, P. (2006). Creating network bridges for university technology transfer: The medici fellowship programme. Technology Analysis $\mathcal{E}$ Strategic Management, 18(1), 71-91.

[31] Bauch, P. A. (2001). School-Community Partnerships in Rural Schools: Leadership, Renewal, and a Sense of Place. Peabody Journal of Education, 76(2), 204-221.

[32] Sanders, M. G. (2001). The Role of “ Community" in Comprehensive School, Family, and Community Partnership Programs. The Elementary School Journal, 102(1), 19-34.

[33] Barringer, B. R., \& Harrison, J. S. (2000). Walking a Tightrope: Creating Value Through Interorganizational Relationships. Journal of Management, 26(3), 367-403. 
[34] Williamson, O. E. (1981). The Economics of Organizations: The Transaction Cost Approach. American Journal of Sociology, 87, 548-577.

[35] Pfeffer, J., Salancik, G. R., The External Control of Organizations: A Resource Dependence Perspective, Stanford University Press.

[36] Freeman, R. E. (1994). The Politics of Stakeholder Theory: Some Future Directions. Business Ethics Quarterly, 4(4), 409-421.

[37] Levinthal, D. A. \& March J. G. (1993). The myopia of learning, Strategic Management Journal, Winter Special Issue, 14, 95-112.

[38] DiMaggio, P., \& Powell, W. (1983). The Iron Cage Revisited: Institutional Isomorphism and Collective Rationality in Organizational Fields. American Sociological Review, 48(2), 147-160.

[39] Williams, T. (2005). Cooperation by design: structure and cooperation in interorganizational networks. Journal of Business Research, 58(2), 223-231.

[40] Epstein, J. L. (1987). Toward a theory of family-school connections: Teacher practices and parent involvement. In K. Hurrelmann, F. Kaufmann \& F. Losel (Eds.), Social intervention: Potential and constraints (pp. 121-136). New York: De Gruyter.

[41] Lanzi, D. (2007). Capabilities, human capital and education. The Journal of Socio-Economics, 36(3), 424-435.

[42] Waddock, S. A. (1991). A Typology of Social Partnership Organizations. Administration $\mathcal{E}$ Society, 22(4), 480-515.

[43] Huggins, R., Johnston, A., \& Thompson, P. (2012). Network Capital, Social Capital and Knowledge Flow: How the Nature of Inter-organizational Networks Impacts on Innovation. Industry and Innovation, 19(3), 203-232.

[44] Storper, M., \&Venables, A. J. (2004). Buzz: Face-to-face contact and the urban economy. Journal of Economic Geography, 4(4), 351-370.

[45] Nohria, N., \& Eccles, R. G. (1992). Networks and organizations: Structure, form, and action. Boston: Harvard Business School Press.

[46] Bienkowska, D., Larsen, K., \&Sörlin, S. (2010). Public-private innovation: Mediating roles and ICT niches of industrial research institutes. Innovation: Management, Policy E Practice, 12(2), 206-216.

[47] Starbuck, E. (2001). Optimizing university research collaborations. Research-Technology Management, 44(1), 40-44.

[48] Harreveld, B., \& Singh, M. (2009). Contextualising learning at the education-trainingwork interface. Education \& Training, 51(2), 92-107. 
[49] Konkola, R., Tuomi-Gröhn, T., Lambert, P., \& Ludvigsen, S. (2007). Promoting learning and transfer between school and workplace. Journal of Education and Work, 20(3), 211-228.

[50] Slaughter, S., \& Leslie, L.L. (1997). Academic capitalism: Politics, policies and the entrepreneurial university. Baltimore, MA: The Johns Hopkins University Press.

[51] Bergek, A., \&Norrman, C. (2008). Incubator best practice: A framework. Technovation, 28(1-2), 20.28 .

[52] Klofsten, M., Heydebreck, P., \& Jones-Evans, D. (2010). Transferring good practice beyond organizational borders: Lessons from transferring an entrepreneurship programme. Regional Studies, 44(6), 791-799.

[53] Matlay, H., \& Carey, C. (2006). Entrepreneurship education in the UK: a critical perspective, ISBE Conference. Cardiff.

[54] Fayolle, A., Kyro, P., \& Ulijn, J. (2005). Entrepreneurship Research in Europe. Edward Elgar Publishing, Northampton, MA.

[55] Nurmi, P., \&Paasio, K. (2007). Entrepreneurship in Finnish universities. Education and Training, 49(1), 56-65.

[56] Katz, J. (2003). The chronology and intellectual trajectory of American entrepreneurship education 1876-1999. Journal of Business Venturing, 18(2), 283-300.

[57] Kuratko, D. F. (2005). The emergence of entrepreneurship education: Development, trends, and challenges. Entrepreneurship Theory and Practice, 29(5), 577-598.

[58] Adcroft, A., Willis, R., \& Dhaliwal, S. (2004). Missing the point? Management education and entrepreneurship. Management Decision, 42(3/4), 521-30.

[59] Sexton, D. L., \& Upton, N. B. (1987). Evaluation of an innovative approach to teaching entrepreneurship. Journal of Small Business Management, 25, 35-43.

[60] Moore, S.A., \& Weiler, B. (2009). Editorial-Tourism-protected area partnerships: stoking the fires of innovation. Journal of Sustainable Tourism,17(2), 129-132.

[61] Yar Hamidi, D., Wennberg, K., \& Berglund, H. (2008). Creativity in entrepreneurship education. Journal of Small Business and Enterprise Development, 15(2), 304-20.

[62] Cavanagh, R. E., Kay, K., Klein, D., \& Meisinger, S. R. (2006). Are they really ready to work? Employers' perspectives on the basic knowledge and applied skills of new entrants to the 21st century workforce: The Conference Board, Partnership for 21st Century skills, Corporate voices for Working Families, and Society for Human Resource Management.

[63] Goldin, C., \& Katz, L. F. (2008). The Race Between Education and Technology. Boston: Harvard University Press. 
[64] Chia, R. (1996). Teaching paradigm shifting in management education: university business schools and the entrepreneurial imagination. Journal of Management Studies, 33(4), 409-28.

[65] Eisenhardt, K. (1989). Building theory from case study research. Academy of Management Review, 14(4), 532-550.

[66] Yin, R. K. (2009). Case study research: Design and methods. London: Sage Publications.

[67] Bryman, A., \& Bell, E. (2003). Business research methods. Oxford: Oxford University Press.

[68] Flick, U. (2006). An Introduction to Qualitative Research, Sage Publications, London.

[69] Bardin, L. (2004). Content Analysis, 3rd Edition. Editions 70, Lisbon.

[70] Dickson, P. H., \& Weaver, K. M. (1997). Environmental determinants and individuallevel moderators of alliance use. Academy of Management Journal, 40, 404-425.

[71] Armistead, C., \& Pettigrew, P. (2004). Effective partnerships: building a sub-regional network of reflective practitioners. The International Journal of Public Sector Management, 17(6/7), 571-585. 